\title{
A NONLINEAR CONTROL MODEL AND OPERATIONAL SUPPORT SYSTEM FOR THE KAINJI HYDROELECTRIC POWER SYSTEM
}

\author{
O. Ogunbiyi ${ }^{1,}{ }^{*}$, C. T. Thomas ${ }^{2}$, I. O. A. Omeiza ${ }^{3}$, J. Akanni ${ }^{4}$ and B. J. Olufeagba ${ }^{5}$ \\ 1, Electrical and Computer Engineering Department, KWARA State University, Malete, KWARA STATE, NIGERIA \\ 2, ELECTRICAL AND INFORMATION ENGINEERING DEPARTMENT, ACHIEVER'S UNIVERSITY, OWO, ONDO STATE, NIGERIA. \\ 3, 4, 5, EleCtRICAL AND ELECTRONICS ENGINEERING DEPARTMENT, UNIVERSITY OF ILORIN, KWARA STATE, NIGERIA \\ E-mail addresses. ${ }^{1}$ biyikan@gmail.com, ${ }^{2}$ corneliustthomas@gmail.com, 3 isaacavazi@yahoo.com, \\ 4 jimaka2005@gmail.com, ${ }^{5}$ benjabezolufsenx@gmail.com
}

\begin{abstract}
Over the past years, hydropower model and control were largely based on classical and linear transfer function, this was motivated by the available control system design techniques that were available and the desire to simplify the design procedure. Such a model is inadequate for dynamic study and design of hydropower station in the presence of uncertainties in the water head, discharge rate, elastic water effect, traveling wave effect, large variation power output and frequency. This research, therefore, focuses on developing a nonlinear model for the Kainji hydroelectric power station. The model relies on the energy conversion principles, inflows, discharge, evaporation rate and number of units on busbar. The parameters of the model were also estimated, and the model validated with an error within $+1.4 \%$ to $-3.6 \%$. The model is expected to be used to determine the optimal control policies for the operation of the station and the release of water to the downstream.
\end{abstract}

Keywords: Hydroelectric Power, Inflow, Model, Operating Head, Turbo-alternator.

\section{INTRODUCTION}

The Kainji Hydroelectric Power System (KHEPS) plays a vital role in the Nigeria energy generation. It is located at $09^{\circ} 51^{\prime} 45^{\prime \prime} N, 04^{0} 36^{\prime} 48^{\prime \prime} E$, it was officially commissioned in February 1969 with a capacity of 320 MW, produced by four Kaplan driven turbo-alternators designated as units 7, 8, 9 and 10, each rated at 80 MW. In 1976, two additional units of Kaplan turbines, units 11 and 12 each rated at $100 \mathrm{MW}$ were added, increasing the installed capacity of the station to 520 MW. In 1978 the installed capacity was increased to $760 \mathrm{MW}$ with the installation of two additional sets of fixed blade machines unit 5 and 6 , each rated at 120 MW.

The Kainji dam is $65 \mathrm{~m}$ in height and about $8 \mathrm{~km}$ in length. The reservoir lake stretches some $136 \mathrm{~km}$ upstream and has a breadth of $24 \mathrm{~km}$ at its widest point. The maximum and minimum head elevation is $141.7 \mathrm{~m}$ and $124 \mathrm{~m}$ respectively above sea level, while the maximum and minimum net operating head are around $42.2 \mathrm{~m}$ and $24 \mathrm{~m}$ respectively with the rated operating head roughly $38 \mathrm{~m}$. The lake has a total capacity of 15 billion cubic meters covering an area of 1270 square kilometres [1 - 3].

The Nigeria national grid is powered from twenty-eight (28) generating stations with total installed capacity of 12,522 MW [4]. The stations are either hydroturbine, steam turbine or gas-fired turbine. The plants are being run by generation companies classified as Privatized (those formerly under the PHCN), National Integrated Power Project (NIPP), and Independent Power Producers (IPPs).

A review of the contributions of the different generating stations to the installed capacity, generating capacity and peak generation shows the pivotal role of KHEPS in the energy generation of Nigeria. As at August 2016, its contribution to the installed capacity was around $6 \%$ while its contribution to the generation was roughly $10 \%$ on the average. This shows that the efficient operation of the station is of great importance to the nation [5]. 
The station lies on the River Niger, which takes its source at Futa Djallon Mountains of Guinea, flowing through Mali, Niger and Nigeria before entering the Atlantic Ocean [6]. The Hydrology of River Niger at Kainji is characterized by two almost distinct inflow peaks named white and black flood. White flood is associated with rainfall within the catchment area of Nigeria between May to October. The peak flow occurs sometimes in the month of September or October $\left(5628 \mathrm{~m}^{3} / \mathrm{s}, 4665 \mathrm{~m}^{3} / \mathrm{s}\right)$. Black flood, on the other hand, originates from the river's source and arrives at Kainji between December and January $[7,8]$.

A review of the performance assessment of KHEPS shows that it has been performing below the install capability due to several issues such as ageing of equipment, fault on equipment and constraints due to the level of water in the reservoir $[9,8,10]$. Various measures are being taken to overhaul the units but there is a crucial issue relating to the latter.

The inflow is stochastic, yet the reservoir must be operated within the allowable head limit and also to discharge sufficient water to optimally operate the downstream station (Jebba Hydropower). Numerous researches have suggested scientific means of managing the inflow such that the system will be operated within a safe limit of operating head. Adoption of these scientific methods is better than prediction of the operating head from experience. Nwobi-Okoye and Igboanugo [11] developed a transfer function model of the inflow such that it allows the prediction of the inflow into the reservoir. The method was based on time series approach, this method seems promising but does not lead to real time control. Ale et al. [7] also suggested an exponential smoothing of the reservoir inflow using exponential smoothening and time series approach, the method does not consider the availability of the unit, a parameter that is very crucial to the level of operating head. The artificial neural network (ANN) approach was used in [12] for the prediction of energy generation in a hydropower station, such a prediction may not be totally acceptable because the operating head depends on the usage and not static parameters.

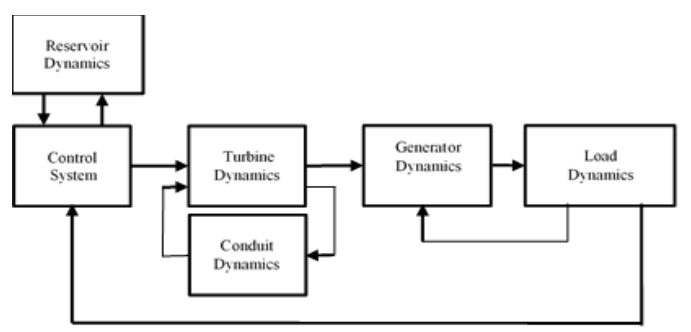

Figure 1a: HEP Subsystem and Dynamics.
Hence this research attempts to develop a model of the power generation at KHEPS, the model emphasises the dependency of power generation on the available operating head. Hence the model suggests how and the duration for the units to be operated such that the station maximise its generation potential without conflicting with the constraints posed on the operating head and discharge to the Jebba Hydroelectric Power Station (JHEPS). A significant importance of the model is that it leads to a real time control system design of the station, this is a breakthrough for control engineers that desire to develop control system for the station. During this work, literatures that developed a similar model could not be found, hence the model was validated by comparing the model prediction of operating head with measured data.

\section{NONLINEAR MODEL OF KHEPS OPERATING HEAD}

To develop a model of the system for designing a control system, the station can be separated into each dynamics subsystem model. The subsystem model can be described by the block diagram of Figure 1, consisting of reservoir dynamics, turbine dynamics, conduit dynamics, generator dynamics, load dynamics and the control system serving as a mediator between the energy source and the load. If the turbine dynamics, conduit and generator dynamics are summed together as a conversion efficiency inside the control system, then the control system serves as the link between the output power and the reservoir dynamics.

Figure 2 shows the schematic structure of the KHEPS with variables affecting the reservoir dynamics and power generation dynamics as a function of head. In the schematic: let the the operating head be represented by $h(m)$, inflow into the reservoir represented by $Q\left(\mathrm{~m}^{3} / \mathrm{s}\right)$, inflow into the penstock represented by $q\left(\mathrm{~m}^{3} / \mathrm{s}\right)$, losses represented by $Q_{L}\left(\mathrm{~m}^{3} / \mathrm{s}\right)$, discharge through spill way $Q_{S}\left(\mathrm{~m}^{3} / \mathrm{s}\right)$, effective surface area represented by $A_{1}\left(\mathrm{~m}^{2}\right)$, area of the scroll casing represented by $A_{2}\left(m^{2}\right)$ while the turbo-alternators are represented by $U_{1}$ to $U_{8}$.

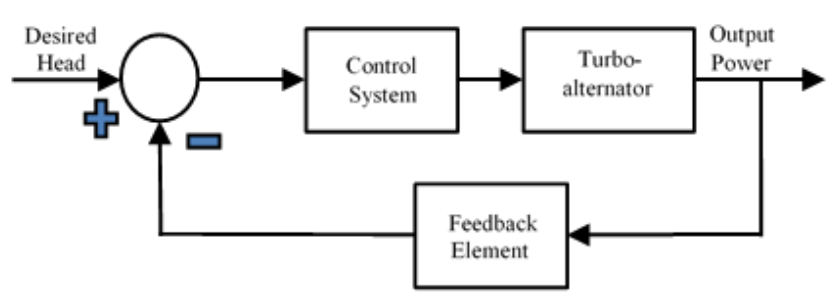

Figure 1b: Control System for KHEPS 


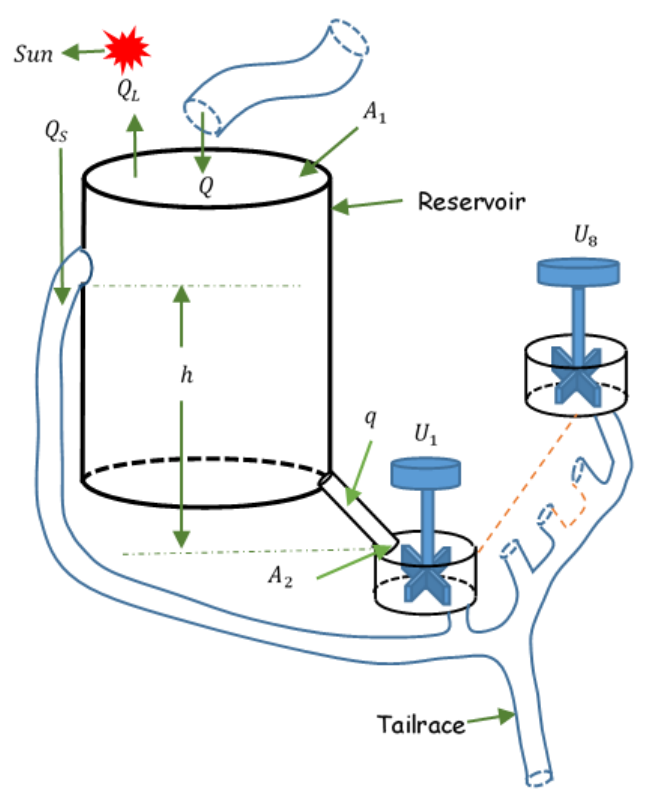

Figure 2: Schematic structure of KHEPS

The electrical power developed $P_{e}(W)$ from a hydroelectric power system can be expressed as:

$$
P_{e}=\eta \rho g h q
$$

Where $\rho$ is the density of water in $\left(\mathrm{kg} / \mathrm{m}^{3}\right), g$ is the acceleration due to gravity $\left(\mathrm{m} / \mathrm{s}^{2}\right)$ and $\eta$ is the conversion efficiency of the turbo-alternator. The flow rate $q$ is related to the velocity of water in the discharge $v_{2}$ by equation (2) which combines with equation (1) to give equation (3). The velocity of the inflow into the reservoir is related to the operating head by applying the Bernoulli's energy equation to the streamline between the input and output of the reservoir [13], resulting into equations (4) and (5).

$$
\begin{aligned}
& q=A_{2} v_{2} \\
& P_{e}=\eta \rho g h A_{2} v_{2} \\
& \rho g h=1 / 2 \rho v_{2}^{2} \\
& v_{2}=\sqrt{2 g h}
\end{aligned}
$$

hence,

$$
q=A_{2} \sqrt{2 g h}
$$

therefore,

$$
P=\sqrt{2} \eta \rho A_{2} g^{3 / 2} h^{3 / 2}
$$

As earlier said, KHEPS has 8 non-homogenous units that can be classified into three groups. A set of four Kaplan turbo-alternators rated $80 \mathrm{MW}$ and designated by $n_{1}$, the two sets of 100 MW Kaplan turboalternators designated by $n_{2}$ and the two sets of 120 MW Francis turbo-alternators represented by $n_{3}$. The Total electrical power developed at any time can be represented by equation (8), which can also be presented as in equation (9).

$$
\begin{gathered}
P=\sqrt{2} n_{1} \eta_{1} \rho A_{2} g^{3 / 2} h^{3 / 2}+\sqrt{2} n_{2} \eta_{2} \rho A_{2} g^{3 / 2} h^{3 / 2} \\
+\sqrt{2} n_{3} \eta_{3} \rho A_{2} g^{3 / 2} h^{3 / 2} \\
P_{T}=\left(\varphi_{1}+\varphi_{2}+\varphi_{3}\right) h^{3 / 2}
\end{gathered}
$$

where, $\varphi_{1}=\sqrt{2} n_{1} \eta_{1} \rho A_{2} g^{3 / 2}, n_{1}$ can take an integer number from 1 to 4

$\varphi_{2}=\sqrt{2} n_{2} \eta_{2} \rho A_{2} g^{3 / 2}, n_{2}$ can take an integer number from 1 to 2

$\varphi_{3}=\sqrt{2} n_{3} \eta_{3} \rho A_{2} g^{3 / 2}, n_{3}$ can take an integer number from 1 to 2

In equation (9), it is obvious that the power generated depends largely on the operating head and the reservoir dynamics is represented by the dynamical head equation.

\section{DYNAMICAL HEAD EQUATION OPERATING HEAD}

For the reservoir of Figure 2 the flow can be described by equation (10).

$$
A_{1} h=\left(Q-Q_{L}-Q_{s}-q\right) t
$$

If equation (2) is substituted for $q$ in equation (10), then;

$$
\frac{d h}{d t}=A_{1}^{-1}\left(Q-Q_{L}-Q_{s}-A_{2} v_{2}\right)
$$

Therefore,

$$
\frac{d h}{d t}=A_{1}^{-1}\left(Q-Q_{L}-Q_{s}-A_{2} \sqrt{2 g h}\right)
$$

Furthermore,

$$
\frac{d h}{d t}=-\sqrt{2 g} A_{1}^{-1} A_{2} h^{1 / 2}+A_{1}{ }^{-1}\left(Q-Q_{L}-Q_{s}\right)
$$

Hence, the dynamical model for the operating head KHEPS with number of units $n$ is expressed as:

$$
\begin{aligned}
\frac{d h(t)}{d t}=-n A_{1}^{-1} & A_{2} \sqrt{2 g h(t)} \\
& +A_{1}^{-1}\left(Q(t)-Q_{L}(t)-Q_{S}(t)\right)
\end{aligned}
$$

Based on the resulting model equation (14), the operating head dynamic can therefore be represented by the block diagram of Figure 3 .

The total electrical power developed at any time can be written in the generic form for control system design as in equations (15a) and (15b), such that $h(t)$ represents the state of the system at time $t . u(t)$ is the control input to the system at time $t$, corresponding to the net inflow into the system while $f$ and $\mathrm{K}$ are nonlinear scalar valued functions.

$$
\begin{gathered}
\dot{h}(t)=f(h(t), u(t)) \\
P(t)=\mathrm{K}(h(t))
\end{gathered}
$$

Since the head equation is nonlinear, it was solved using the Adams-Moulton Numerical Techniques with Runge-Kutta Starter. 


\section{CALIBRATION: MODEL PARAMETER ESTIMATION}

The above model equations provide a framework for relating forces, dimensions and inputs to give a dynamical representation, the actual values that best relate the model output must be determined in a calibration / tuning process. The following model parameters were estimated from measured data: effective surface area $\left(A_{1}\right)$ of the reservoir, effective area of the scroll Casing $\left(A_{2}\right)$ and effective evaporation loss $\left(Q_{L}\right)$.

\subsection{Estimation of Effective Surface Area ( $\left.A_{1}\right)$}

From the physical measurement of the inflow and head, it is possible to estimate $A_{1}$ by studying the data around an area where the response seems linear. In Figure 4, the inflow into the reservoir and head are plotted against time for a duration where the head changes are almost linear. The data used were obtained from Transmission Company of Nigeria (TCN), National Control Centre (NCC) Oshogbo. Then,

$$
\begin{aligned}
A_{1} \times \Delta h & =\int_{t_{1}}^{t_{n}}\left(Q_{(t)}-q_{(t)}\right) d t \\
A_{1} & =\frac{1}{\Delta h} \int_{t_{1}}^{t_{n}}\left(Q_{(t)}-q_{(t)}\right) d t
\end{aligned}
$$

It should be noted that the surface area varies with the head but the variation from the calculated effective value will be very minimal around the operating range. From equation (17) and Figure (4), $A_{1}=$ $883,208,571.43 \mathrm{~m}^{2}$.

\subsection{Estimation of Effective Area of the Scroll Casing}

In estimating the effective area of the scroll casing $\left(A_{2}\right)$, the area was calculated per day using equations (18) and (19) from $1^{\text {st }}$ of Jan. to $31^{\text {st }}$ of Dec. 2013. The calculated values were plotted against time as shown in Figures 5 . The median in each case was taken as $A_{2}$.

$$
\begin{aligned}
& q_{i}=A_{2 i} n_{i} \sqrt{2 g h_{i}}, \quad i=1,2,3, \ldots, 365 \\
& A_{2 i}=\frac{1}{n_{i} \sqrt{2 g h_{i}}} q_{i}
\end{aligned}
$$

where $n_{i}$ represents the number of operating units on day $i, q_{i}$ is the total station discharge on day $i$. Hence given the observation for year 2013, the median value of $A_{2 i}$ was selected as the effective value in the model such that $A_{2}=8.55005 \mathrm{~m}^{2}$

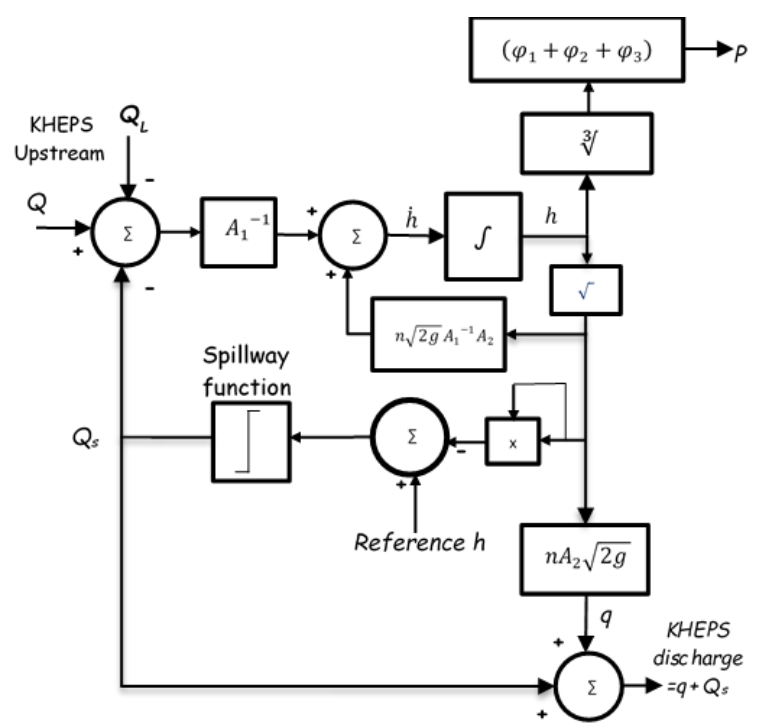

Figure 3: Block Diagram of the Control Model for KHEPS

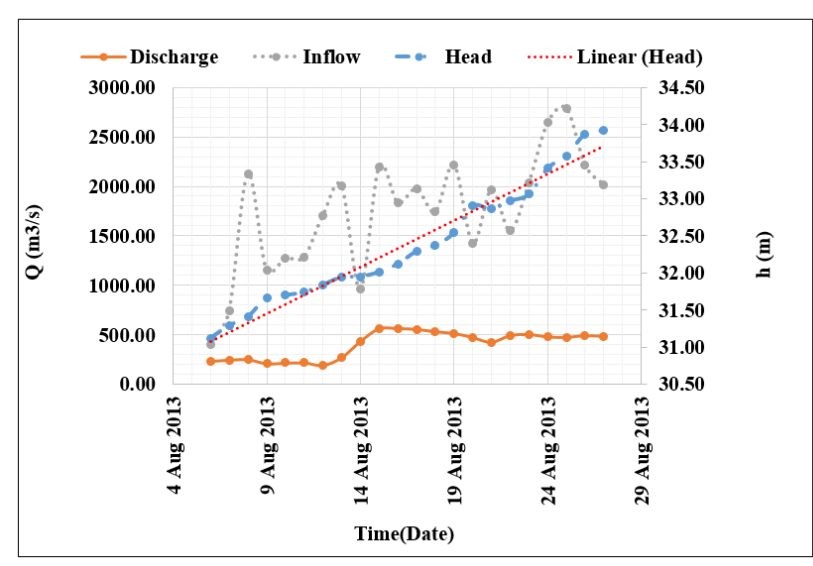

Figure 4: Estimation of Effective Surface Area for KHEPS

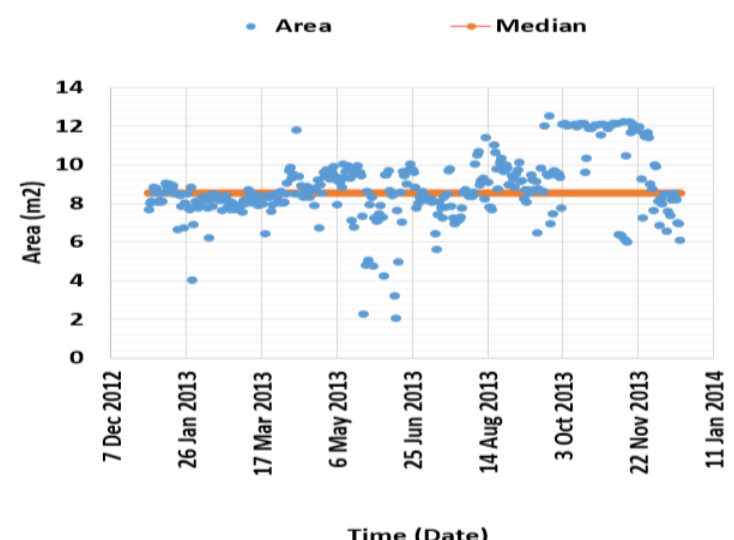

Figure 5: Estimation of Effective Area of the Scroll Casing for KHEPS

\subsection{Estimation of Effective Evaporation Losses for KHEPS}

Numerous factors are responsible for the losses in the reservoir but the prominent is that of the evaporation. 
An expression for the evaporation loss was estimated from observations between 1974 and 2009 for KHEPS. Monthly maximum, minimum and average evaporation loss were plotted in each case in Figure 6 , the average value was mathematically modelled and presented in equations (20) [14].

$$
\begin{aligned}
& \text { Qevp, } K=0.0003 m^{6}-0.0126 m^{5}+0.0845 m^{4} \\
&+ 1.8323 m^{3}-25.699 m^{2} \\
&+88.123 m+7.267
\end{aligned}
$$

Where $m$ can take a numerical value between 1 to 12 , representing month of the year.

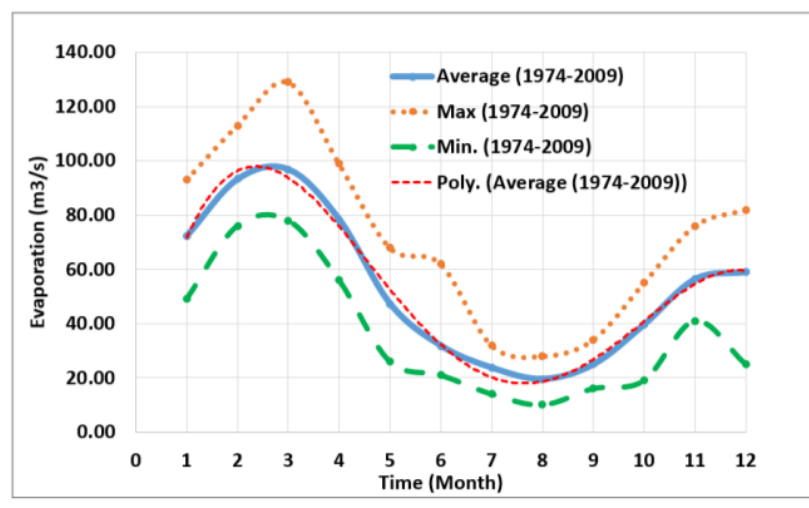

Figure 6: Estimation of Evaporation Loss for KHEPS

\section{RESULTS AND DISCUSSION}

So far, the dynamical system has been modelled and calibrated by estimating its parameters. A numerical solution was also computed for the resulting model. The model was validated by comparison between computed head and the observed head. Other data used in the validation include the inflows, the number of operating units per day and evaporation losses. The results obtained are as presented in Figures 7 (a) to (d).

The curves show that the model relatively predicts the performance of KHEPS with minimal error. If the present reservoir head is known, the inflow and spill way function, the reservoir head can then be predicated to a high level of accuracy. Since the power generation is directly proportional to the head, the model makes it possible for the operators to estimate the obtainable power.

Figure 8 presents the percentage error between the predicted head and the measured head with the maximum error within $+1.4 \%$ to $-3.6 \%$, this means that the model is dependable and sufficiently predicts the dynamical change in head and maximum power obtainable.

Numerous factors may be responsible for the slight deviation of the computed head from the measured value but a significant one is that the estimated evaporation losses may vary from the actual evaporation losses. Also, the actual number of units operating per day may not reflect the value used in the model. A machine may not work for a larger part of the day but in as much as it was operating as at the time the reading was taken, it will be assumed that it was operating for a whole day. These among others are responsible for the difference between the measured head and computed head.

\section{POTENTIAL PERFORMANCE OF KHEPS AND JHEPS UNDER DIFFERENT CONDITIONS}

A library of macro routines using Microsoft EXCEL-VBA was developed to compute a numerical solution for the models, calibrate and validate the models. The macros can serve as a computer model for extensive investigation of the potential performance of KHEPS hydropower station under different conditions, it can be used for training hydropower station operators and planning tool managers.

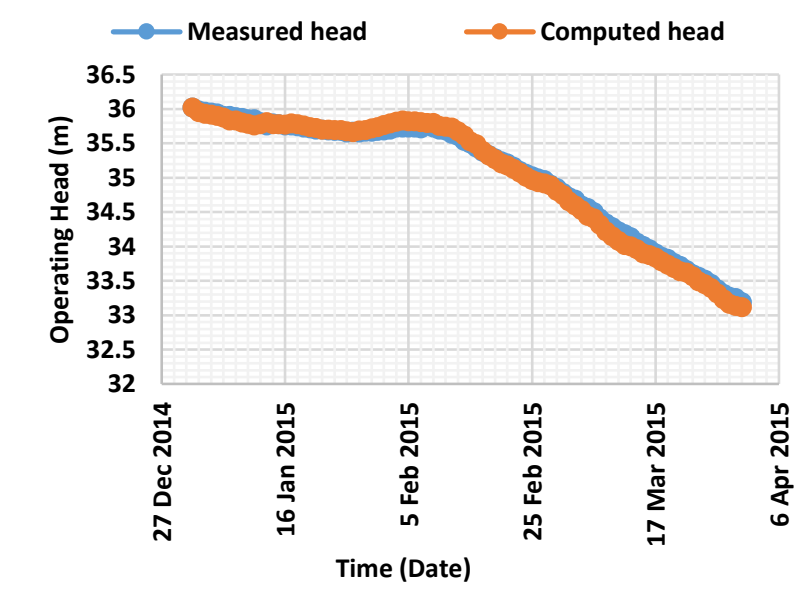

(Jan. - Mar. 2013)

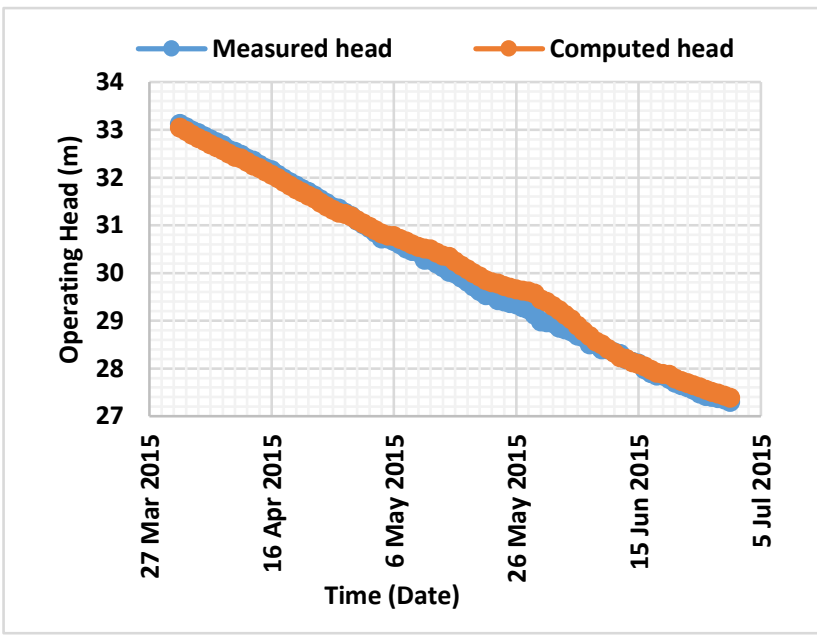

(Apr. - Jun. 2013) 


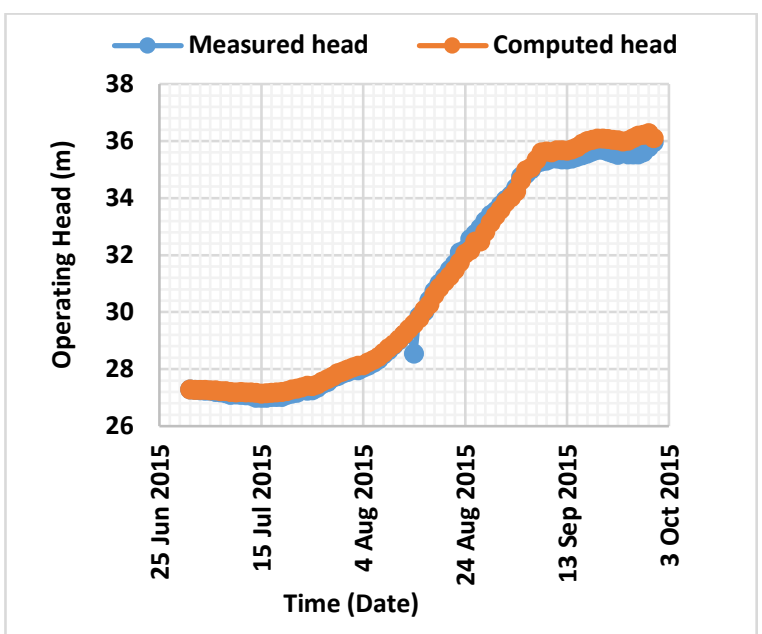

(Jul. - Sep. 2013)

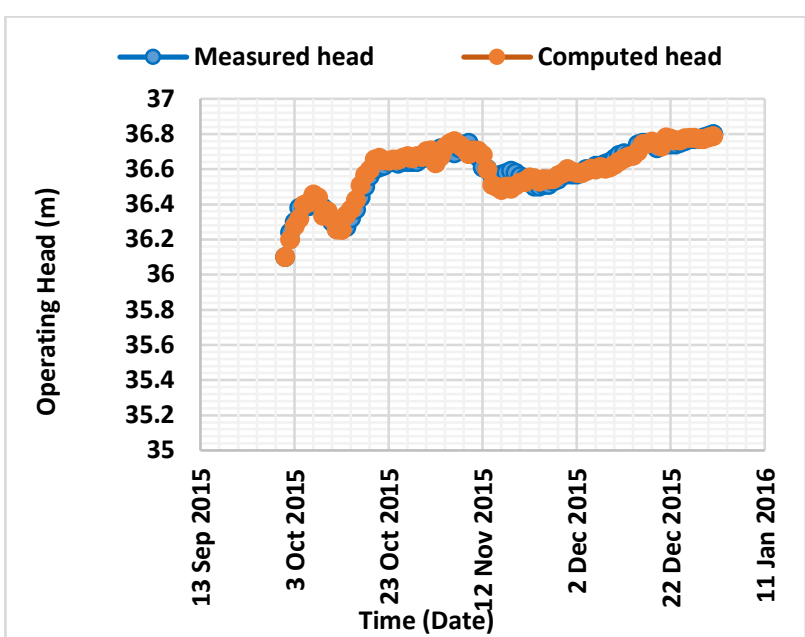

(Oct. - Dec. 2013)

Figure 7: Comparison of Observed Head with Computed Head in 2015

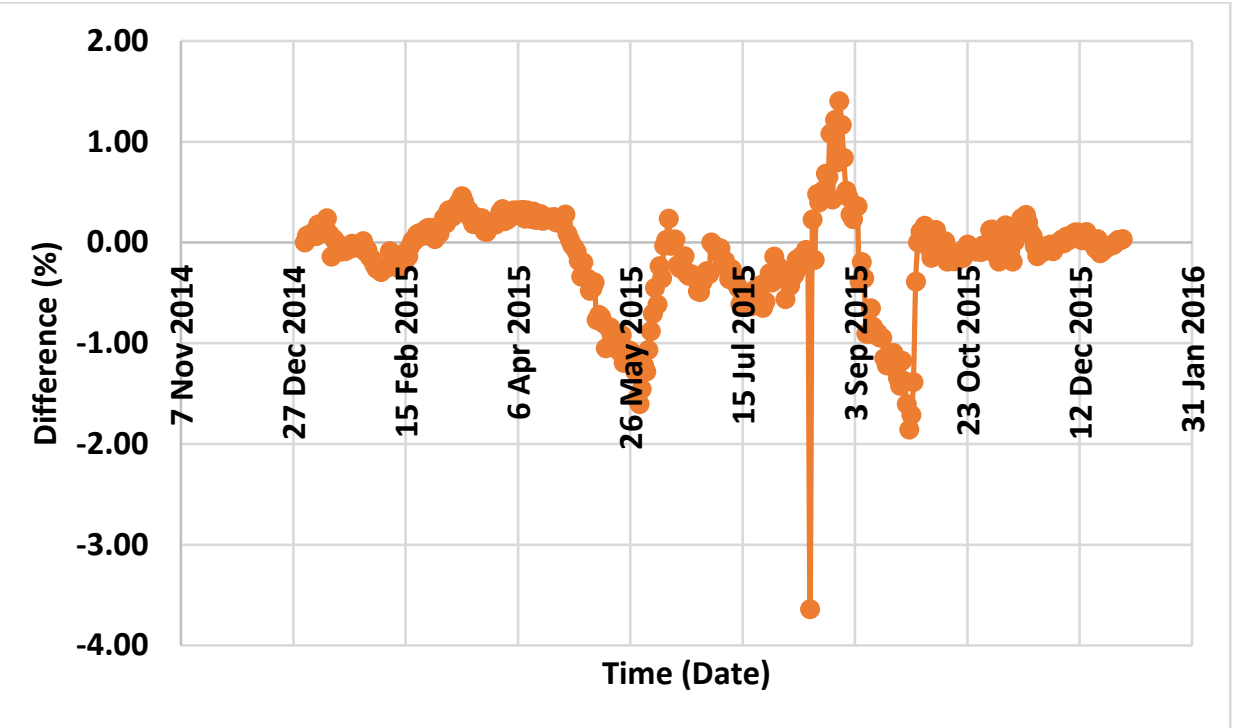

Figure 8: Error between Measured Head and Computed Head in 2015 Versus Time

Figure 9 (a) shows the effect of negligible or no inflow on KHEPS. The curves show the time in which different number of machines can be operated when there is no inflow. If there is low or no inflow into KHEPS reservoir for one day $(86400 \mathrm{~s})$, the head will fall faster with all the 8 units operating than just one unit. If the reservoir starts at maximum head of $37 \mathrm{~m}$, in one day the head will fall to $36.8 \mathrm{~m}$ if 8 units are working, 36.90 $\mathrm{m}$ if 4 units are working and $36.97 \mathrm{~m}$ with only one machine.

Similarly, the plots in Figure 9(b) gives important information in the operation of KHEPS as per how many units can be in operation such that the head does not fall below a level in one day, given that the inflow into the reservoir is known.

If a load line is drawn on the graphs, the point of intersection of the curve with the line gives the flow that will keep the operating head constant at the intersecting value when certain number of units are in operation.

\section{CONCLUSION}

In this paper, the mathematical models describing the dynamics of the KHEPS reservoirs was formulated from energy conservation principles and the model was tuned with estimated system physical parameters as well as essential inputs and outputs that sustain the dynamics. The result was a nonlinear differential equation, describing the head dynamics and related to the maximum power generation. The model was integrated numerically a procedure for estimating model parameters using observations of inputs were discussed and the model validated. The Nonlinear model is therefore recommended for use in the optimal control system design and performance study of KHEPS. 


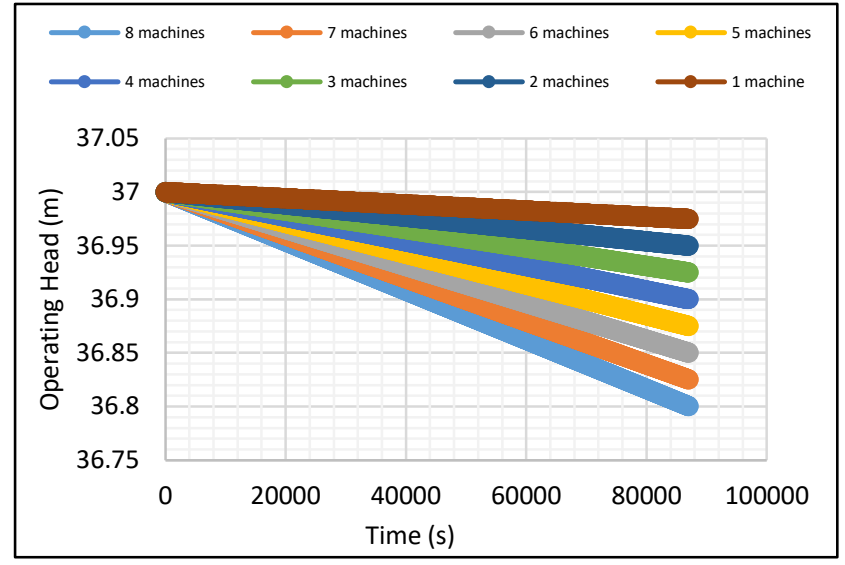

(a)

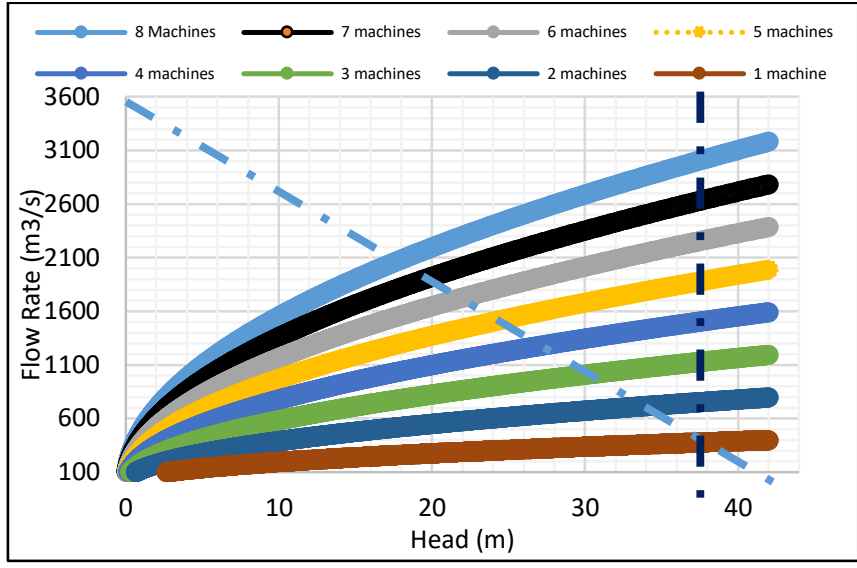

(b)

Figure 9: (a) Effect of Drought on KHEPS and JHEPS Reservoir, (b) Flow Rate versus Operating Head for KHEPS

\section{REFERENCES}

[1] J. O. Aribisala, "Deterministic Operational Analysis of Kainji-Jebba Hydroelectric Power System," Ilorin, 1989.

[2] A. W. Salami, "Operational Performance of Water management Models for Hydropower System under Reservoir Inflow Forecast," Ilorin, 2007.

[3] PTFP, Roadmap to Power Sector Reform: A Customer-Driven Sector-Wide Plan, Abuja: Presidental Task Force on Power, 2010.

[4] TCN-NCC, Daily Operational Report, Oshogbo, 2017.

[5] TCN-NCC, Daily Operational Report, Oshogbo, 2016.

[6] O. Jimoh, "Optimized Operation of Kainji Reservoir," Assumption University Journal of Technology, vol. 12, no. 1, pp. 34-42, 2008.

[7] T. O. Ale, K. E. Alowolodu, J. O. Babatola and B. J. Olufeagba, "Inflow Forecasting for Kainji Dam using Time Series Model," International Journal of Mathematical Archive, vol. 2, no. 12, 2011.

[8] O. D. Jimoh, "Operation of Hydropower in Nigeria," 2015. [Online]. Available: http://www.unilorin.edu.ng/nachrede/Operation $\% 20$ of\%20Hydropower\%20System\%20in\%20N
igeria\%20By $\% 20 \mathrm{D}$

$\mathrm{r} \% 20$

O\%20D\%20Jimoh.htm. [Accessed 1 July 2015].

[9] A. S. Sambo, B. Gabar, I. H. Zarma and M. M. Gaji, "Electricity Generation and the Present Challenges in the Nigeria Power Sector," Journal of Energy and Power Engineering, vol. 6, no. 7, p. 1050, 2012.

[10] T. O. Ale, "Analysis, Modeling and Simulation of Reliability of Generation of Kainji Hydro Power Station, Nigeria," Ondo State, Nigeria, 2014.

[11] C. C. Nwobi-Okoye and C. A. Igboanugo, "Performance evaluation of hydropower generation system using transfer function modelling," Elsevier: Electrical Power and Systems, vol. 43, pp. 245 - 254, 2012.

[12] T. S. Abdulkadir, A. W. Salami, A. R. Anwar and A. G. Kareem, "'Modelling of Hydropower Reservoir Variables for Energy Generation: Neural Network Approach," Ethiopian Journal of Environmental, vol. 6, no. 3, pp. 310-316, 2013.

[13] J. F. Douglas , J. M. Gasiorek, J. A. Swaffied and L. B. Jack, Fluid Mechanics, 5th ed., India: Pearson, 2012.

[14] O. Ogunbiyi, "Modelling and Optimal Control of the Cascaded Kainji-Jebba Hydroelectric Reservoir," University of Ilorin, 2018. 